\title{
EL NUEVO DECRETO ANDALUZ SOBRE VIVIENDAS PARTICULARES DE USO TURÍSTICO. ANÁLISIS A LA LUZ DE LA AGENDA EUROPEA PARA LA ECONOMÍA COLABORATIVA
}

\author{
Alejandro Román Márquez \\ Universidad de Sevilla
}

\section{RESUMEN}

Con ocasión del análisis del recientemente aprobado Decreto andaluz sobre viviendas particulares de uso turístico se van a poner de manifiesto las cuestiones más relevantes y polémicas de su régimen jurídico, haciendo una comparativa con aspectos destacados de otras regulaciones autonómicas en la materia, poniendo de relieve las principales novedades pero también las ausencias más destacadas de la norma andaluza, y todo ello interpretado conforme a la también recientemente aprobada "Agenda europea para la economía colaborativa", documento esencial para conocer la opinión de la Unión Europea sobre estas actividades y, fundamentalmente, sobre los nuevos mecanismos de intermediación online en el sector turístico.

Palabras clave: Viviendas turísticas, economía colaborativa, Agenda europea, intermediación online.

The new Andalusian Decree on private homes for tourist use. Analysis under the European agenda for colaborative economy

\section{ABSTRACT}

During the analysis of the recently approved Andalusian Decree on private homes for tourist use will be highlighted the most important and controversial issues of their legal

Recibido: 13 de octubre de 2016

Devuelto para su revisión: 21 de abril de 2017

Aceptado: 11 de mayo de 2017

Departamento de Derecho Administrativo. Universidad de Sevilla. Campus Ramón y Cajal. C/ Enramadilla 18-20, 41018 SEVILLA (España). E-mail: aroman2@us.es 
status, making a comparison with highlights of other regional regulations on the matter, foregrounding the main developments but also the most notable absences of the Andalusian rule, and all interpreted under the recently adopted "European Agenda for collaborative economy", an essencial document to know the opinion of the European Union on these activities and, fundamentally, about new online trading mechanisms in the tourism sector.

Keywords: Tourist homes, collaborative economy, European agenda, collaborative platforms.

\section{INTRODUCCIÓN}

Andalucía se ha sumado recientemente al grupo de Comunidades Autónomas que regulan por vía reglamentaria el uso turístico de las viviendas particulares. Con esta finalidad ha aprobado el Decreto 28/2016, de 2 de febrero, de las viviendas con fines turísticos y de modificación del Decreto 194/2010, de 20 de abril, de establecimientos de apartamentos turísticos. De su encabezado se desprende que esta norma está dividida en dos partes esencialmente diferentes: una primera que reglamenta la dedicación, por parte de sus propietarios, de viviendas de naturaleza residencial a la actividad de alojamiento turístico; y una segunda que contiene diversas modificaciones del régimen jurídico de los apartamentos turísticos, modalidad tradicional de establecimiento de alojamiento turístico y ajena, por lo tanto, al ámbito de las viviendas particulares. La principal diferencia entre las viviendas particulares de uso turístico y los apartamentos turísticos está en que, mientras que en las primeras únicamente se proporciona al usuario un servicio de alojamiento, en los segundos se añade a éste una serie de servicios turísticos de carácter complementario, como la limpieza diaria o el servicio de conserjería/recepción ${ }^{1}$. Este criterio diferenciador ya fue recogido expresamente por la Orden de 17 de enero de 1967, sobre ordenación de apartamentos, bungalows y otros alojamientos similares de carácter turístico (Preámbulo), reiterándose posteriormente por la doctrina especializada (Verdera Izquierdo, 2009: 13-19; Campuzano Tomé, 2015: 1.219-1.220)

El objeto de este trabajo se centra, por su trascendencia y actualidad, en el análisis del nuevo régimen jurídico de las viviendas particulares dedicadas al uso turístico en Andalucía, poniendo de relieve sus diferencias y similitudes más relevantes respecto de regímenes análogos en otras Comunidades Autónomas, señalando las novedades introducidas en esta materia, así como las eventuales lagunas y los principales problemas interpretativos que pudiesen existir. Todo ello, además, interpretado conforme a las previsiones de la nueva Agenda europea para la economía colaborativa, recientemente aprobada por la Comisión Europea.

\section{PRESUPUESTO, CAUSAS Y FINES DEL DECRETO 28/2016, DE 2 DE FEBRERO}

El ejecutivo andaluz fundamenta la elaboración de esta norma en la modificación operada en la Ley 29/1994, de 24 de noviembre, de Arrendamientos Urbanos (en ade-

1 Sobre tal diferenciación resulta ilustrativa la sentencia del Tribunal Supremo de 16 de junio de 1982 (RJ $1982 / 5828)$. 
lante LAU), por la Ley 4/2013, de 4 de junio, de medidas de flexibilización y fomento del mercado de alquiler de viviendas ${ }^{2}$. Recuérdese cómo el nuevo texto de la LAU excluyó expresamente de su ámbito de aplicación "[...] la cesión temporal de uso de la totalidad de una vivienda amueblada y equipada en condiciones de uso inmediato, comercializada o promocionada en canales de oferta turística y realizada con finalidad lucrativa, cuando esté sometida a un régimen especifico, derivado de su normativa sectorial" (art. 5 letra e). La causa de dicha exclusión, reproducida por la exposición de motivos del reglamento andaluz, está en el aumento significativo y continuado, en los años precedentes, del uso de viviendas privadas como alojamientos turísticos ${ }^{3}$. En la raíz de dicho aumento el Decreto andaluz sitúa las nuevas formas de viajar, el deseo de los turistas de mantener una relación más directa con los residentes del destino elegido y los nuevos canales de comercialización de la oferta turística, entre los que destacan los nuevos portales de Internet ${ }^{4}$. Dentro de éstos, y aunque el Decreto andaluz no aluda a ellos expresamente, destacan especialmente aquéllos que han sido incluidos, con mayor o menor justificación, dentro del fenómeno conocido como "economía colaborativa". La regulación andaluza de los canales de comercialización de la oferta turística será objeto de reflexión en un epígrafe específico de este trabajo.

Como justificación de esta norma, el ejecutivo andaluz parte del aserto de que "[...] la oferta de este canal es muy amplia y no siempre va acompañada, como sería deseable, de un excelente servicio, ni de una mínima garantía", sin olvidar que, como señala previamente, el uso cada vez más habitual de viviendas particulares como alojamientos turísticos "[...] podría estar dando cobertura a situaciones de intrusismo y competencia desleal, que van en contra de los destinos turísticos"5. Tal problemática orienta toda la regulación contenida en esta norma, de forma que su objetivo principal será "establecer una mínimas garantías de calidad y seguridad para las personas usuarias", del cual se desprenden a su vez una serie de objetivos o fines parciales y complementarios del objetivo principal ${ }^{6}$ :

2 Sobre esta modificación de la Ley de Arrendamientos Urbanos vid. Román Márquez (2014); o, desde una perspectiva más genérica, VVAA (2013); y Blanco Carrasco (2014), entre otros.

3 Circunstancia que ya fuera puesta de manifiesto, en su momento, por el Plan Nacional e Integral de Turismo (PNIT) 2012-2015. Conforme a este documento, el incremento habría sido del 15,9\% durante el año 2011 (Ministerio de Industria, Energía y Turismo, 2012: 90). Tal y como refleja un estudio realizado por la Universidad Ramón Llull/ESADE Business School-Law School, durante el año 2014 el 14 \% de los turistas en España se hospedaron en viviendas de este tipo, siendo la modalidad habitual para 9 de cada 10 turistas que optaron por esta clase de alojamiento, predominando indiscutiblemente el turista extranjero (79\% sobre el total) y una edad media de 46,8 años. En cuanto al arrendador, se trata mayoritariamente de pequeños propietarios con solamente un inmueble dedicado a esta actividad, cuyos ingresos complementan habitualmente los obtenidos con otras actividades. El canal predilecto para la contratación de estas viviendas es Internet (98 \%), y dentro de éste las webs especializadas en alquiler de viviendas vacacionales. El grado de satisfacción es muy alto, siendo recomendado por 9 de cada 10 usuarios (ESADE, 2015).

4 No hace mención, sin embargo, a la gran cantidad de viviendas de segunda residencia existentes en España, lo que constituye para la doctrina especializada una de las causas principales del auge de esta actividad. Sobre esta cuestión vid. Gili I Fernández (2003) y Serrano Martínez (2011).

5 Ambas citas tomadas de la exposición de motivos del Decreto 28/2016 (párrafos segundo y tercero). En la misma línea que CEHAT (2013) y EXCELTUR (2015).

6 Exposición de motivos del Decreto 28/2016 (párrafo cuarto y ss.). 
a) Respetar las obligaciones de seguridad pública impuestas por la Ley Orgánica 4/2015, de 30 de marzo, de protección de la seguridad ciudadana, a las actividades de hospedaje (registro documental -libro-registro- e información sobre los usuarios de estos establecimientos - partes de entrada-).

b) Proteger físicamente, y como consumidor, a los usuarios de servicios turísticos, lo que se traducirá en la exigencia de una serie de requisitos y garantías a cumplir por los propietarios de las viviendas privadas dedicadas al turismo.

c) Proteger el medio ambiente y el entorno urbano de los impactos que genera la actividad turística sobre el territorio, la comunidad sobre la que se integra y la convivencia vecinal. Este objetivo parte de la premisa de configurar a la actividad turística como una actividad sostenible, de tal forma que sea posible conservar los recursos turísticos para su explotación continuada en el tiempo.

d) Eliminar la clandestinidad de estos alojamientos turísticos -a través de la creación de un censo de viviendas con fines turísticos de Andalucía, para lo que se dispone su inscripción en el Registro de Turismo de Andalucía- y la competencia desleal respecto de la oferta turística reglada, luchar contra el fraude y garantizar unos requisitos mínimos básicos de infraestructuras y de calidad, ejercitando sus potestades inspectora y sancionadora en esta materia.

\section{EL OBJETO DEL DECRETO ANDALUZ: LAS VIVIENDAS PARTICULARES DEDICADAS AL ALOJAMIENTO TURÍSTICO. MODALIDADES Y RELA- CIÓN CON EL PLANEAMIENTO URBANÍSTICO Y LA PROPIEDAD HORI- ZONTAL}

A pesar de que el nuevo epígrafe e) del artículo 5 de la LAU deja claro que las viviendas particulares de uso turístico deberán cederse al usuario "en su totalidad", el Decreto andaluz desoye esta exigencia e introduce, como novedad con respecto al resto de regulaciones autonómicas, una doble modalidad de vivienda particular de uso turístico: las cedidas en su totalidad y las que lo hacen por habitaciones. Sin embargo, las diferencias en cuanto al régimen jurídico de ambas modalidades van a ser escasas. En primer lugar, en las viviendas ofertadas por habitaciones su propietario deberá residir en la vivienda (art. $5.1 \mathrm{~b}$ ), por lo que en éstas existirán espacios “comunes", compartidos por el propietario y los huéspedes (como el comedor, salón, cocina o aseos) y otros de uso exclusivo por parte de éstos últimos (como mínimo, sus respectivas habitaciones). El Decreto andaluz no establece explícitamente la obligatoriedad de espacios comunes, por lo que, sensu contrario, nada impide que junto con los dormitorios pueda cederse al huésped el uso exclusivo de alguna otra estancia de la vivienda ( $v . g r$. uno de los cuartos de baño). La clave estará en que dichos espacios, en el caso de que se consideren esenciales para que una persona pueda residir en una vivienda, deberán estar, como mínimo, duplicados, puesto que si solamente existe uno de ellos y se cede su uso exclusivo al huésped de ninguna forma podrá considerarse que el propietario reside en la vivienda. Así, por ejemplo, si se pretende reservar un cuarto de baño o una cocina al huésped es necesario que existan dos o más en la vivienda, puesto que si solamente se dispone de uno de ellos, la privación de su uso por parte del propietario impediría considerar que éste reside efectivamente en la vivienda. 
Esta cuestión se mantiene dentro de cauces más o menos pacíficos en tanto se circunscribe a espacios que de ninguna forma son considerados necesarios para residir en una vivienda, como sucede, por ejemplo, con el jardín, el solarium, las instalaciones deportivas, la piscina o las plazas de aparcamiento. Sin embargo, la cuestión se complica cuando se toman en consideración otros espacios cuya consideración como esenciales para la residencia es, cuanto menos, discutible. Así ocurre, por ejemplo, con el salón o el comedor de la vivienda. ¿Estas estancias resultan imprescindibles para poder residir en una vivienda o son meramente accesorios y, por tanto, es posible su cesión en exclusiva a los usuarios turísticos? Partiendo de la tesis de que la función básica de una vivienda es proporcionar un espacio para el descanso, la higiene personal y la preparación de alimentos a su inquilino ${ }^{7}$ (al menos en la cultura occidental, ya que existen otras culturas, como la asiática, que prescinden habitualmente de la tercera de las funciones referidas), es perfectamente posible ceder en exclusiva a los huéspedes el uso de ambos espacios, ya que tanto el descanso como el consumo de alimentos -previamente elaborados en la cocina de la vivienda- pueden realizarse perfectamente en el dormitorio del propietario de la vivienda, sin necesidad de disponer necesariamente de un salón o de un comedor. En definitiva: cocina, cuarto de baño y lugar para el descanso (dormitorio u otra dependencia debidamente acondicionada al efecto) serán los espacios a los que, siguiendo la interpretación expuesta, deberá poder acceder el propietario para que pueda considerarse que éste reside efectivamente en su vivienda y, en consecuencia, pueda cederse a los usuarios turísticos por habitaciones. Obviamente, tal interpretación está sujeta a un eventual desarrollo normativo de estas previsiones y, fundamentalmente, a la opinión de los tribunales, cuya jurisprudencia servirá para aclarar las cuestiones planteadas. En cualquier caso, si finalmente se considerase que no se cumplen los parámetros fijados en el Decreto andaluz para la cesión turística de una vivienda por habitaciones, siempre será posible arrendarla -igualmente por habitaciones- sujetándose al régimen general de la LAU. No podrá calificarse en ningún caso como alquiler turístico, ni utilizar los canales de intermediación turística, ni autorizarse como tal, ni sus usuarios gozarán de la protección dispensada al turista, pero seguirá siendo posible su arrendamiento a terceros al tiempo que su propietario continúa residiendo en la vivienda.

Volviendo a la exposición de las diferencias entre las viviendas particulares cedidas en su totalidad y por habitaciones, la segunda de ellas consiste en que, en éstas últimas, el Decreto andaluz permite expresamente que se utilicen "las denominaciones internacionales reconocidas para este tipo de alojamiento" (art. 5.1 b): por ejemplo, las recogidas

7 Una pista sobre cuáles son las estancias esenciales que cualquier vivienda debe poseer para ser considerada como tal se haya en la Orden de la Consejería de Agricultura, Pesca y Medio Ambiente de 1 de marzo de 2013, por la que se aprueban las Normativas Directoras para la Ordenación Urbanística en desarrollo de los artículos 4 y 5 del Decreto 2/2012, de 10 de enero, por el que se regula el régimen de las edificaciones y asentamientos existentes en suelo no urbanizable en la Comunidad Autónoma de Andalucía. Conforme a este reglamento, estas viviendas deberán “[...] incluir como mínimo una estancia que realice las funciones de estar $y$ descanso, un equipo de cocina y un cuarto de aseo independiente" (norma $6^{\mathrm{a}}$ epígrafe $a$ ). Ante la ausencia de mejores criterios orientativos en el Código Técnico de la Edificación-aprobado por el Real Decreto 314/2006, de 17 de marzo-y careciendo la Comunidad Autónoma andaluza de normativa específica en materia de licencias de primera ocupación y cédulas de habitabilidad, habrá que estar, para determinar cuáles son las estancias mínimas de una vivienda, a lo que señale en cada municipio su planeamiento urbanístico. 
en la Statistical Classification of Economic Activities in the European Community (NACE Rev. 2) ${ }^{8}$, en la Standard International Classification of Tourism Activities (SICTA) ${ }^{9}$ (Vid. Gismondi y Mirto: 2002) o en la Norma ISO 18513:2003 Hotels and other types of tourism acommodation. Terminology, entre otros.

La tercera reside en la capacidad máxima de ambas modalidades. Si bien el número máximo de plazas alojativas susceptibles de ser ofertadas por cualquier vivienda de uso turístico vendrá siempre determinado por lo dispuesto en su licencia de ocupación, dicho número nunca podrá ser superior, en el caso de viviendas cedidas en su totalidad, a quince plazas, y en el caso de viviendas cedidas por habitaciones, a seis plazas, sin que en ninguna de las dos modalidades puedan superarse las cuatro plazas por habitación (art. 5.2) y sin que a estos efectos tenga relevancia alguna la edad de los huéspedes ${ }^{10}$.

La cuarta y última diferencia está en que mientras que la vivienda cedida en su totalidad puede ser arrendada por cualquier persona con título suficiente para ello (por ejemplo, el arrendatario de la vivienda puede dedicarla al uso turístico - "subarrendarla"- siempre que el contrato de arrendamiento suscrito con el propietario de la vivienda lo permita), sólo su propietario puede ceder la vivienda por habitaciones, ya que es el único autorizado por el reglamento andaluz para residir en la misma junto a los turistas. Están excluidas de esta posibilidad, por tanto, aquellas personas que residan en la vivienda en virtud de derechos diferentes a la propiedad, como los propios arrendatarios, los usufructuarios o los precaristas. El ejecutivo andaluz no justifica esta limitación a la libertad económica de tales personas.

Con independencia de la modalidad de vivienda turística de que se trate, el Decreto andaluz exige que todas las viviendas de uso turístico estén ubicadas en inmuebles radicados en suelo de uso residencial (art. 3.1). Surge así un problema de compatibilidad entre la ordenación urbanística de la ciudad y la normativa turística, pues la planificación urbanística de los municipios españoles no suele aceptar la coexistencia de los usos turístico y residencial sobre una misma área o sector de la ciudad, y mucho menos sobre una misma parcela o inmueble ${ }^{11}$. La exclusión de tal coexistencia de usos se justifica por las incomodidades que habitualmente genera la actividad turística -esencialmente en materia de contaminación acústica y deterioro de las zonas comunes del edificio- para los residentes habituales del inmueble. Profundizando en esta incompatibilidad de usos, el propio Decreto andaluz califica el alojamiento en viviendas de uso turístico como un "servicio turístico" de los regulados en la Ley 13/2011, de 23 de diciembre, del Turismo de Andalucía (art. 2.1, en adelante LTA), de forma que no existan dudas sobre la naturaleza turística de esta actividad. Se produce así un conflicto entre la naturaleza de estos alojamientos -servicios turísticos, esto es, uso turístico del suelo- y el suelo sobre el que

8 Oficina Europea de Estadística (Eurostat), Office for Official Publications of the European Communities, Luxemburgo, 2008.

9 Clasificación Internacional Uniforme de Actividades Turísticas (CIUTAT), Organización Mundial del Turismo (OMT/WTO), 1993.

10 Por ejemplo, el Decreto balear 20/2015, de 17 de abril, excluye de este cómputo las plazas efectivamente destinadas y ocupadas por niños hasta 12 años, pero también las destinadas el personal de vigilancia, de limpieza o doméstico que pueda pernoctar en el alojamiento (art. 106.7).

11 Solamente, y de forma excepcional, en relación a algunas pensiones u hostales ubicados en edificios históricos del centro de algunas ciudades. Sobre la compatibilidad de usos turístico y residencial en relación a las viviendas particulares de uso turístico vid. Guillén Navarro (2015: 135-137). 
se asientan -de uso residencial-, conflicto que no puede ser resuelto atendiendo al reparto de competencias entre las diferentes entidades territoriales, pues tanto el urbanismo como el turismo son materias atribuidas a las Comunidades Autónomas, lo que genera una contradicción en el seno del propio Ordenamiento Jurídico autonómico cuya solución no ha sido positivizada aún.

Algunas normas autonómicas sobre la materia incluyen previsiones genéricas acerca de la necesidad de que las viviendas particulares de uso turístico se adapten a la planificación urbanística del espacio sobre el que se asientan. Así lo hacen, entre otras, el Decreto 17/2015, de 26 de febrero, por el que se regulan los establecimientos de alojamiento en la modalidad de apartamentos turísticos en la Comunidad de Castilla y León, el cual dispone que "[1] as edificaciones o emplazamientos donde se ubiquen los establecimientos de alojamientos en la modalidad de apartamentos turísticos deberán cumplir la normativa vigente en materia de urbanismo, construcción y edificación, sanidad y consumo, seguridad, prevención de incendios, protección civil, accesibilidad y supresión de barreras físicas y sensoriales, higiene, protección de medio ambiente y cualquier otra que resulte de aplicación" (Disposición adicional primera); o el Decreto 80/2015, de 5 de mayo, por el que aprueba el Reglamento de las viviendas de uso turístico en Aragón, el cual prevé que entre el contenido mínimo de la declaración responsable realizada por el titular de la vivienda figure obligatoriamente la relativa a "[...] la compatibilidad del uso [de la vivienda] con el planeamiento urbanístico del municipio [...]" (art. 14.2 e). Se trata, en cualquier caso, de previsiones que no aportan ninguna solución práctica al problema planteado pues, como se ha señalado, el planeamiento urbanístico prohíbe de forma generalizada la compatibilidad de usos turístico y residencial sobre un mismo inmueble, por lo que si se requiere respetar las previsiones de aquél será prácticamente imposible legalizar ninguna de estas viviendas. Es necesario, por tanto, que se articulen mecanismos jurídicos que permitan compatibilizar las previsiones del planeamiento urbanístico con la naturaleza inequívocamente turística de las viviendas particulares dedicadas a esta actividad.

En cualquier caso ¿Cómo justifica el ejecutivo andaluz esta mezcolanza de usos, en principio incompatibles, sobre un mismo inmueble? No lo hace de forma expresa, pero de la lectura de la exposición de motivos del Decreto 28/2016 parece inferirse del carácter accesorio que se le atribuye a la explotación turística del inmueble sobre su uso residencial, que sería la actividad principal del propietario (párrafo cuarto in fine). La explotación turística de la vivienda estaría tolerada por cuanto se trata de una actividad accesoria, pudiendo entenderse ésta como temporal, por lo que las incomodidades irrogadas a la población residente no serían continuas en el tiempo. Sin embargo, el Decreto andaluz no establece, como tampoco lo hacen el resto de regulaciones autonómicas, ningún límite temporal global al uso turístico de la vivienda, por lo que ésta puede permanecer cedida de forma ininterrumpida a diferentes usuarios turístico durante todo el año, de modo que las eventuales incomodidades generadas por la actividad turística no serían puntuales sino continuas. Lo que sí hace el Decreto andaluz es fijar un límite temporal parcial al uso turístico de la vivienda: no es posible ceder la vivienda a una misma persona por tiempo superior a dos meses continuados (art. 1.2 b). Esta previsión en ningún caso termina con el problema expuesto, por lo que no existiría ninguna supuesta accesoriedad temporal entre los usos turístico y residencial que permita justificar su compatibilidad en estas viviendas. 
Tampoco podría justificarse la compatibilidad de usos en una supuesta excepcionalidad de las viviendas de uso turístico en relación al inmueble en el que se ubican, pues tampoco existen límites absolutos en relación al número máximo de viviendas dedicadas al uso turístico en cada inmueble, por lo que pueden llegar a ser mayoría o, incluso, la totalidad de aquéllas ${ }^{12}$. Sí existe, al igual que en el caso anterior, un límite relativo al número de viviendas dedicadas al uso turístico: ninguna persona puede ser propietario de más de tres viviendas dedicadas al uso turístico en un mismo inmueble o grupo de inmuebles -contiguos o no-(art. 1.2 d). Si este límite se supera serán considerados apartamentos turísticos, quedando sometidos a su régimen jurídico, contenido en el Decreto 194/2010, de 20 de abril, de establecimientos de apartamentos turísticos.

Descartadas pues la excepcionalidad temporal y numérica, la justificación de la admisibilidad de la coexistencia de usos sobre un mismo inmueble por parte del ejecutivo andaluz debe encontrarse en motivos de mera oportunidad. Ante la imposibilidad de eliminar esta oferta clandestina -numerosa y dispersa-, el ejecutivo andaluz, a semejanza de la mayoría de sus homólogos, opta por su legalización a través de la imposición de una serie de requisitos que protejan los bienes jurídicos que justifican su regulación, enumerados en su propia exposición de motivos: seguridad jurídica, protección de los usuarios de servicios turísticos, protección del medio ambiente y del entorno urbano, y eliminación de la clandestinidad y de la competencia desleal.

Por último, el Decreto andaluz guarda silencio acerca del papel que juegan las comunidades de propietarios en aquellos casos - muy habituales- en los que las viviendas forman parte un inmueble sometido al régimen de la propiedad horizontal. Para que tales viviendas puedan ser destinadas al uso turístico es necesario que lo permitan los estatutos y reglamentos que rigen la comunidad de propietarios, si bien no es obligatorio que el uso turístico esté entre los permitidos expresamente por aquéllos, bastando con que no se prohíba expresamente ${ }^{13}$. En caso de que las normas que rigen la comunidad de propietarios guardasen silencio acerca del uso turístico de la vivienda (o, incluso, aunque lo permitieran expresamente), solamente podría prohibirse éste si puede demostrase que se trata -en el caso concreto o bien de forma general- de un uso molesto o dañoso para la comunidad ${ }^{14}$. Y es que no puede olvidarse que la normativa turística autonómica no puede excepcionar el régimen jurídico de la propiedad, de competencia estatal. En cualquier caso, siempre será posible modificar los estatutos de la comunidad de propietarios para permitir o prohibir expresamente el uso turístico de las viviendas que componen la comunidad, si bien se trata de una vía complicada pues requiere la unanimidad del total de los propietarios que, a su vez, representen el total de las cuotas de participación en la comunidad ${ }^{15}$. Ya desde 2010 encontramos Comunidades Autónomas que sí recogen expresamente la necesidad de que el uso turístico de las viviendas no se encuentre limitado por los estatutos de la comunidad

12 Lo que, paradójicamente, terminaría con los problemas de convivencia expuestos, al no existir en tales inmuebles residentes con los que coexistir.

13 Vid. la sentencia del Tribunal Supremo n ${ }^{\circ} 535 / 2013$, de 12 de septiembre.

14 Usos prohibidos por el artículo 7.2 de la Ley 49/1960, de 21 de julio, sobre propiedad horizontal. Sobre esta cuestión vid. Fuentes-Lojo Rius (2016), en el que analiza pronunciamientos judiciales tanto a favor como en contra de considerar la actividad turística como molesta o dañosa para la comunidad de propietarios.

15 Artículo 17.6 de la Ley 49/1960, de 21 de julio, sobre propiedad horizontal. 
de propietarios, como hace el Decreto catalán 164/2010, de 9 de noviembre, de regulación de las viviendas de uso turístico (art. 3.3), previsión que continúa vigente en el Decreto 159/2012, de 20 de noviembre, de establecimientos de alojamiento turístico y de viviendas de uso turístico (art. 68.6), que deroga al anterior. Otras Comunidades Autónomas han seguido el ejemplo catalán, como Aragón -Decreto 80/2015, de 5 de mayo, por el que se aprueba el Reglamento de las viviendas de uso turístico de Aragón (Disposición adicional única)-, Canarias -Decreto 113/2015, de 22 de mayo, por el que se aprueba el Reglamento de las viviendas vacacionales de la Comunidad Autónoma de Canarias (art. 12.2)- o Asturias -Decreto 48/2016, de 10 de agosto, de viviendas vacacionales y viviendas de uso turístico (arts. 27 b) y 30.1)-. Ante la generalización de estas previsiones se hace difícil encontrar justificación para este olvido del ejecutivo andaluz, salvo que haya considerado como algo obvio el respeto debido a las normas - externas e internas- que rigen las comunidades de propietarios.

\section{LA EXPLOTACIÓN COMERCIAL DE LAS VIVIENDAS PARTICULARES DE USO TURÍSTICO Y LOS CANALES DE COMERCIALIZACIÓN PREVISTOS EN EL DECRETO 28/2016. LA ECONOMÍA COLABORATIVA DESDE LA ÓPTICA DE LA UNIÓN EUROPEA Y SU PAPEL EN LA MATERIA}

El Decreto andaluz parte de la base de que la cesión de las viviendas particulares debe tener siempre naturaleza comercial, es decir, debe perseguir un beneficio económico para su propietario, por lo que se excluyen las cesiones de naturaleza gratuita al señalar que "[s]e entiende por fines turísticos aquellas [...] donde se vaya a ofrecer mediante precio el servicio de alojamiento [...] (art. 3.1)". Así lo reitera el propio Decreto al excluir expresamente de su ámbito de aplicación "[1]as viviendas que, por motivos vacacionales o turísticos, se cedan, sin contraprestación económica" (art. 1.2 a $)^{16}$.

Pero, además de la onerosidad, el Decreto andaluz exige también las notas de habitualidad y finalidad turística respecto de dichas cesiones, para lo que el Decreto andaluz establece un presunción iuris tamtum (arts. 3.1 in fine y 3.2.): se presumirá que se cede la vivienda de forma habitual y con fines turísticos cuando ésta sea comercializada o promocionada en canales de oferta turística. El propio Decreto aporta además una interpretación auténtica de lo que debe entenderse por canales de oferta turística: “[s]e considerarán [...] [como tales] las agencias de viaje, las empresas que medien u organicen servicios turísticos y los canales en los que se incluya la posibilidad de reserva de alojamiento" (art. 3.3). Las dos primeras "modalidades" de canales de oferta turística señalados por el ejecutivo andaluz -agencias de viaje y empresas que medien u organicen servicios turísticos- son ambas vías clásicas de comercialización de productos turísticos. Más interesante resulta la referencia a los canales en los que se incluya la posibilidad de reserva de alojamiento. El decreto andaluz, como adelanta en su exposición de motivos (párrafo tercero), se está

16 Quedan excluidos así los intercambios de viviendas, en los que no existe contraprestación económica entre sus propietarios, y que formarían parte del denominado "turismo colaborativo puro" (Guillén Navarro, 2015: 103). En el caso de cesiones gratuitas su régimen jurídico no se encontraría tampoco en la LAU, que excluye de su ámbito objetivo el arrendamiento de vivienda sin contraprestación económica por su uso (arts. 17 y ss), por lo que deberá recurrirse a la regulación de figuras civiles como el comodato o el precario. 
refiriendo a la comercialización de plazas turísticas a través de Internet, y al referirse a estos canales como operadores diferentes a las agencias de viajes y empresas intermediarias tradicionales, parece indudable que está pensando en experiencias encuadrables en el fenómeno de la economía colaborativa, por contraposición a las formas clásicas de comercialización de productos turísticos. Como expone DOMÉNECH PASCUAL (2015:61), "[e]conomía colaborativa es la expresión usualmente utilizada en castellano para designar lo que en inglés se conoce como sharing economy, peer-to-peer economy, mesh, collaborative economy o collaborative consumption, expresiones más o menos equivalentes, al margen de los particulares matices de significado que cada una de las cuales encierra. Con ellas se alude a los nuevos sistemas de producción y consumo de bienes y servicios que surgen a principios del siglo XXI y que aprovechan las posibilidades abiertas por los recientes avances de las tecnologías informáticas para intercambiar y compartir dichos bienes y servicios". Como es sabido, las plataformas digitales conforman un marco utilizado de forma creciente para la comercialización de viviendas particulares de uso turístico, a través de portales de Internet que ponen en contacto directo a propietarios y turistas, sin necesidad de recurrir a los intermediarios tradicionales del mercado turístico ${ }^{17}$.

Pero la llamada economía colaborativa es un fenómeno polémico, incluso en su propia acepción (Bostman, 2013; Guillén Navarro e Íñiguez Berrozpe, 2015: 14), que plantea numerosos desafíos en materia de condiciones de acceso al mercado, fiscalidad, derechos laborales, régimen de responsabilidad o protección de consumidores y usuarios. La Unión Europea se muestra favorable a este fenómeno por entender que constituye un instrumento inmejorable para crear nuevas oportunidades de negocio y dinamizar la economía (Goudin, 2016). Con el objetivo de mitigar la ausencia de regulación de este fenómeno a nivel comunitario y homogeneizar las soluciones diversas -e incluso contradictorias- que varios Estados Miembros han dado a este fenómeno, la Comisión Europea ha publicado recientemente la Comunicación de 2 de junio de 2016 al Parlamento Europeo, Consejo, Comité Económico y Social, y Comité de las Regiones titulada "Una agenda europea para la economía colaborativa"18. La filosofía que impregna las páginas de este documento parte de la necesidad de someter las iniciativas encuadrables dentro de la economía colaborativa a un régimen jurídico equivalente al existente para la economía tradicional, que no suponga un obstáculo para su desarrollo pero que tampoco cree situaciones de competencia desleal entre ellas (Comisión Europea, 2016:16).

De forma extremadamente sintética, y centrando el análisis de la Agenda europea en los canales de comercialización -turística, en este caso- ${ }^{19}$, la Comisión Europea parte de la consideración general de las plataformas colaborativas -collaborative platforms- como intermediarios que suministran servicios de la sociedad de la información ${ }^{20}$ y que, como

17 Sobre esta materia vid. Calderón Monge, Izquierdo Yustaq y Ruiz Vega (2007), Guevara Plaza y Cerezo Medina (2015) o Guillén Navarro e Íñiguez Berrozpe (2015).

18 Bruselas, 2 de junio de 2016, COM(2016) 365 final.

19 Para un análisis más pormenorizado de este documento vid. Román Márquez (2017).

20 Siempre que ofrezcan sus servicios a cambio de remuneración, a distancia, por medios electrónicos -online- y a petición individualizada del receptor de tales servicios, lo que ocurre en la generalidad de los intermediarios turísticos online de las viviendas particulares de uso turístico, como es el caso, por ejemplo, de Airbnb, Homelidays o Homeaway. 
tales, no pueden estar sometidos en ningún caso a autorización específica previa o instrumento equivalente ${ }^{21}$. Pero no todas las plataformas colaborativas quedan encuadradas en este régimen tan favorable y flexible de los servicios de la sociedad de la información. La Comisión Europea excluye a las "falsas" plataformas colaborativas, que bajo esta apariencia esconden una naturaleza de meros prestadores profesionales de servicios - professional services providers-, y que ofrecen servicios "subyacentes" - underlying- y "adicionales" a los auténticos servicios de la sociedad de la información. Para identificarlos la Comisión instituye la teoría del control o influencia significativa: cuando los intermediarios entre los proveedores de servicios - en este caso, los propietarios de las viviendas particularesy los consumidores -turistas- ejerzan sobre los primeros un control o influencia de esta naturaleza deberá considerarse que tales intermediarios no son auténticas plataformas colaborativas, sino meros prestadores profesionales de servicios, que no ofertan verdaderos servicios de la sociedad de la información sino otros servicios de naturaleza subyacente o adicional a éstos. Para identificar el carácter significativo del control o de la influencia ejercida sobre el proveedor de servicios, la Agenda europea aporta tres criterios que deberán cumplirse cumulativamente ${ }^{22}$ :

a) Que el intermediario determine el precio final del servicio (no se cumpliría este requisito si únicamente lo recomienda o si el proveedor puede alterar el fijado inicialmente por aquél);

b) Que el intermediario establezca términos y condiciones obligatorios para el proveedor de servicios que determinen su relación con el usuario ( $v$.gr. instrucciones obligatorias o cláusulas de mantenimiento en el mercado); y

c) Que el intermediario ostente la propiedad de los bienes esenciales para la prestación del servicio.

Cuando estos requisitos se cumplan, tales actividades deberán calificarse como ajenas a la economía colaborativa, entendida ésta como parte de la "sociedad de la información", y será posible que estas falsas plataformas colaborativas puedan quedar sujetas a la regulación de su sector de actividad -en este caso, a la legislación turística de cada Estado Miembro-, incluyendo las autorizaciones administrativas previas (si bien con los requisitos y limitaciones establecidas por la Directiva 2006/123/CE de servicios, los cuáles serán comentados en el epígrafe específicamente dedicado a los requisitos de acceso al mercado de las viviendas andaluzas de uso turístico).

La Agenda europea para la economía colaborativa posee una eficacia jurídica muy limitada al estar contenida en una comunicación de la Comisión Europea, acto unilateral atípico del Derecho comunitario derivado -soft law-que ni siquiera está previsto en el artículo 288

21 Tal y como establece el artículo 4 de la Directiva 2000/31/CE, de 8 de junio de 2000, relativa a determinados aspectos jurídicos de los servicios de la sociedad de la información, en particular el comercio electrónico en el mercado interior (Directiva sobre el comercio electrónico).

22 Así como otros criterios de naturaleza "indicativa", como aquellos supuestos en los que la plataforma colaborativa hace frente a los costes y asume los riesgos relacionados con la prestación de los servicios; o la existencia de una relación laboral entre la plataforma colaborativa y el proveedor del servicio. No serán, por el contrario, criterios indicativos del control de la plataforma sobre el proveedor del servicio el uso de mecanismos de clasificación -ratings- o reseñas/críticas -reviews- (Comisión Europea, 2016: 6-7). 
del Tratado de Funcionamiento de la Unión Europea. Este documento, de naturaleza mucho más política que jurídica, tiene su utilidad a la hora de interpretar el resto del Ordenamiento Jurídico Europeo y, sobre todo, para anticipar la posición de las Instituciones Comunitarias ante el relevante fenómeno de la economía colaborativa. En tal sentido, los poderes públicos estatales y autonómicos tienen en esta comunicación un instrumento que les exhorta, pero también orienta, para construir un régimen jurídico de los intermediarios online de servicios turísticos respetuoso con la filosofía proactiva y liberalizadora de la Unión Europea.

Para finalizar el análisis de los instrumentos de comercialización de las viviendas turísticas en el Decreto andaluz debe hacerse mención a otra cuestión problemática: la consideración o no de las agencias inmobiliarias como canales de oferta turística. A pesar de que no existe unanimidad en la doctrina (ad exemplum, Campuzano Tomé, 2015: 1.230), y de que el propio Decreto 28/2016 no las menciona expresamente, puede considerarse que la expresión utilizada por el ejecutivo andaluz "empresas que medien u organicen servicios turísticos" es lo suficientemente amplia e inclusiva como para considerar que el Decreto, al definir los canales de oferta turística, atiende a la actividad del comercializador y no a su específica naturaleza jurídica, por lo que las agencias inmobiliarias que ejercen de intermediarias entre los propietarios de las viviendas y los usuarios turísticos deben ser consideradas verdaderos canales de oferta turística, y con independencia de que tal mediación se haga presencialmente (en las oficinas de la inmobiliaria) o a través de Internet, en cuyo caso entrarían igualmente dentro de la categoría de "canales en los que se incluya la posibilidad de reserva de alojamiento" (art. 3.3). Es cierto que las agencias inmobiliarias no han ofertado tradicionalmente servicios turísticos ${ }^{23}$, como exige el primero de los dos incisos del Decreto reproducidos, pero desde el mismo momento en que esta norma considera expresamente al "alojamiento en viviendas con fines turísticos" como un servicio turístico al mismo nivel que los recogidos en la $\mathrm{LTA}^{24}$, tal objeción pierde su razón de ser. Incluso la jurisprudencia más reciente se decanta por considerar a las agencias inmobiliarias como un canal más de la oferta turística cuando realicen labores de intermediación en esta materia, como hacen las sentencias del Tribunal Superior de Justicia de las Islas Baleares n ${ }^{0} 799 / 2006$, de 5 de octubre (Fundamento de Derecho cuarto) y no 225/2011, de 29 de marzo (Fundamento de Derecho segundo); así como las del Tribunal Superior de Justicia de las Islas Canarias n $n^{\circ} 376 / 2013$, de 8 de noviembre (Fundamento de Derecho tercero); y no 25/2015, de 9 de enero (Fundamento de Derecho segundo y cuarto) ${ }^{25}$.

En definitiva, el ejecutivo andaluz opta por una noción abierta y amplia de canal de oferta turística, cuya naturaleza y adecuación al concepto formulado por el Decreto 28/2016 deberá ser analizado caso por caso. Se aleja así de otras soluciones más rígidas, como la ideada por la Comunidad Autónoma balear que, en aras a una "mejor información y seguridad jurídica”, atribuye a la Administración competente la elaboración y publica-

23 Pues hasta la aprobación del Decreto 28/2016 la cesión de viviendas particulares para uso turístico no formaba parte del catálogo de servicios turísticos de la Comunidad Autónoma andaluza: vid. art. 28 LTA.

24 A diferencia de lo que hace, por ejemplo, el Decreto catalán 159/2012, de 20 de noviembre, de establecimientos de alojamiento turístico y de viviendas de uso turístico, que excluye implícitamente la consideración de servicios turísticos para las viviendas particulares de uso turístico (art. 3.2).

25 A pesar de no versar sobre materia turística, también resulta interesante lo manifestado por el Tribunal Superior de Justicia de Castilla y León (sentencia $\mathrm{n}^{\circ} 1.352 / 2005$, de 30 de junio) acerca de la naturaleza de las actividades realizadas por las inmobiliarias y su relación con la protección de consumidores y usuarios. 
ción online de una lista actualizada de los canales que se consideren de comercialización turística $^{26}$. Sin embargo, el propio Decreto balear, consciente de la excesiva rigidez de esta previsión, señala a continuación que en ningún caso " [...] se pued[e] considerar una lista cerrada, en el sentido de que no implicará que un canal que no esté incluido en esta lista no se pueda considerar, por razones justificadas, también canal de comercialización turística", dando al traste con la pretendida seguridad jurídica que propugna.

\section{LAS VIVIENDAS EXCLUÍDAS DEL ÁMBITO DE APLICACIÓN DEL DECRETO 28/2016}

El artículo 1.2 del Decreto andaluz contiene el listado de situaciones excluidas de su ámbito de aplicación. Algunas de éstas ya han sido comentadas, como aquellas viviendas cedidas sin contraprestación económica. Otro tanto ocurre con las viviendas contratadas por tiempo superior a dos meses de forma continuada a una misma persona. En este segundo caso su régimen jurídico estará en la LAU, siendo de aplicación el correspondiente al arrendamiento por temporada de naturaleza vacacional ${ }^{27}$. En tercer lugar, también se ha comentado la exclusión de los conjuntos formados por tres o más viviendas pertenecientes a una misma persona titular o explotadora ubicados en un mismo inmueble o grupo de éstos, contiguos o no. El régimen jurídico de estos conjuntos será, como se ha señalado, el de los apartamentos turísticos -contenido en el Decreto 194/2010, de 20 de abril-.

La única exclusión que queda por referir es la relativa a las viviendas destinadas a alojamiento turístico que se ubiquen en el medio rural. En tales casos su régimen jurídico, por expresa decisión del Decreto 28/2016, deberá buscarse en el artículo 48 LTA ${ }^{28}$ y en el Decreto andaluz 20/2002, de 29 de enero, de Turismo en el Medio Rural y Turismo Activo. Es necesario conocer, por tanto, qué debe entenderse por "medio rural" en el ámbito de la normativa turística andaluza. Para ello debe acudirse a la definición recogida en el artículo 3 del referido Decreto 20/200229, el cuál considera medio rural aquél en el que se desa-

26 Art. 107.8 del Decreto 20/2015, de 17 de abril, de principios generales y directrices de coordinación en materia turística; de regulación de órganos asesores, de coordinación y de cooperación del Gobierno de las Illes Balears, y de regulación y clasificación de las empresas y de los establecimientos turísticos, dictado en desarrollo de la Ley 8/2012, de 19 de julio, de Turismo de las Illes Balears.

27 Que forma parte de la heterogénea categoría de "arrendamientos para uso distinto del de vivienda", en los que se incluye, además de los arrendamientos por temporada de cualquier naturaleza, los que tengan como finalidad ejercer en la finca actividades de naturaleza "[...] industrial, comercial, artesanal, profesional, recreativa, asistencial, cultural o docente, cualquiera que sean las personas que los celebren" (art. 3.2 LAU).

28 Recuérdese que este precepto conceptualiza las viviendas turísticas de alojamiento rural como aquéllas “[...] situadas en el medio rural en las que se preste únicamente el servicio de alojamiento, y que son ofertadas al público, para su utilización temporal u ocasional, con fines turísticos, una o más veces a lo largo del año, sin que en ningún caso la prestación del servicio exceda, en conjunto, de tres meses al año" (art. 48.1 LTA). En esta modalidad sí existe una limitación temporal global a la explotación turística de la vivienda, inexistente, como se ha señalado, en el caso de viviendas particulares de uso turístico.

29 Tal y como hace, ad exemplum, el artículo 15 del Decreto andaluz 194/2010, de 20 de abril, que regula los establecimientos de apartamentos turísticos, el cual se remite a la interpretación auténtica del concepto de medio rural contenida en el Decreto 20/2002 para integrar la modalidad apartamentos turísticos rurales. Idénticas remisiones hacen los Decretos andaluces 164/2003, de 17 de junio, de ordenación de los campamentos de turismo (modalidad de campamento de turismo rural, artículo 8.1 b); y 47/2004, de 10 de febrero, de establecimientos hoteleros (modalidad establecimientos hoteleros rurales, art. 34). 
rrollen predominantemente actividades agrícolas, forestales, pesqueras de carácter fluvial y ganaderas. Se trata de un concepto jurídico indeterminado que necesitará de integración en el supuesto concreto. Por el contrario, no tendrán en ningún caso la consideración de medio rural:

a) Las zonas de protección de las carreteras y sus áreas y zonas de servicio $^{30}$;

b) El terreno situado en la zona de influencia del litoral-conforme a la definición que de este espacio hace la Ley 7/2002, de 17 de diciembre, de Ordenación Urbanística de Andalucía, en su artículo 10.1.A.i- o, tras ella, una distancia igual o menor a quinientos metros, siempre que, en este último caso, la vía de acceso a la playa desde el alojamiento turístico no supere los 1.500 metros $^{31}$.

c) Los núcleos de población que conforme al padrón actualizado excedan de 20.000 habitantes.

d) Las zonas próximas a fábricas, industrias, vertederos, instalaciones o actividades que provoquen efectos contaminantes, ruidos o molestias que afecten al turista. El Decreto 20/2002 hace un reenvío expreso, para encontrar tales actividades, a los Anexos I y II de la Ley andaluza 7/1994, de 18 de mayo, de Protección Ambiental. Sin embargo, esta norma fue derogada en su totalidad por la Ley 7/2007, de 9 de julio, de Gestión Integrada de la Calidad Ambiental ${ }^{32}$. Las referencias a las actividades contaminantes o molestas deben entenderse hechas, por lo tanto, a las contenidas en el Anexo I de esta última ("categorías de actuaciones sometidas a los instrumentos de prevención y control ambiental"). Además, el Decreto 20/2002 hace un segundo reenvío a la Orden de la Consejería de Turismo y Deporte de la Junta y Deporte que se apruebe para la especificación de las distancias con respecto a tales zonas. Salvo error u omisión, tal Orden no ha sido aprobada a día de hoy ${ }^{33}$. Para salvar esta eventual laguna, la propia disposición transitoria séptima del Decreto 20/2002 ("Delimitación de zonas no consideradas como medio rural") permite no aplicar esta excepción hasta tanto no se apruebe y entre en vigor la referida Orden, por lo que, en la actualidad, las zonas próximas

30 Reguladas en la Ley 8/2001, de 12 de julio, de Carreteras de Andalucía, la cual regula cuatro zonas de protección de las carreteras: la de dominio público adyacente, la de servidumbre legal, la de afección y la de no edificación (cuyas características y dimensiones se regulan en este texto legal). Por lo que respecta a las áreas y zonas de servicio, las primeras son aquellos elementos funcionales de la carretera, afectos al servicio público viario, destinados a facilitar la seguridad y comodidad de sus usuarios, y que pueden incluir estaciones de suministro de carburantes, establecimientos de alojamiento turístico y de restauración, así como talleres de reparación de vehículos u otros servicios análogos (art. 13). Las zonas de servicio son espacios de titularidad privada con instalaciones y servicios destinados a cubrir las necesidades de la circulación, incluyendo servicios análogos a los existentes en las áreas de servicio (art. 14).

31 Este apartado fue redactado de conformidad con la Disposición adicional tercera del Decreto 47/2004, de 10 de febrero, de establecimientos hoteleros.

32 Vid. la Disposición derogatoria única (número 1, letra $a$ ) de esta ley.

33 Para el desarrollo del Decreto 20/2002 se aprobaron dos Órdenes de la Consejería de Turismo y Deporte de la Junta de Andalucía, ninguna en relación a esta materia: la Orden de 20 de marzo de 2003, que establece obligaciones y condiciones medioambientales para la práctica de las actividades integrantes del turismo activo (BOJA de 4 de abril de 2003, $\mathrm{n}^{\circ}$ 65); y de 19 de septiembre de 2003, que aprueba los distintivos de los alojamientos turísticos en el medio rural y de los mesones rurales (BOJA de 1 de octubre de 2003, $n^{\circ}$ 189, parcialmente derogada). 
a actividades contaminantes y/o molestas siguen pudiendo considerarse medio rural y, por lo tanto, no existe ningún impedimento para ubicar en las misas establecimientos dedicados al alojamiento rural.

Excepcionalmente, el titular de la Dirección General de Planificación Turística podrá declarar como medio rural determinados municipios o áreas integrados en alguno de los apartados reseñados cuando tales espacios pertenezcan a entornos "especialmente pintorescos", posean un "relevante valor paisajístico" o se desarrollen en ellos "actividades eminentemente artesanales" (art. 3.3 del Decreto 20/2002).

Por último, el Decreto andaluz no incluye en su articulado dos exclusiones presentes en otras regulaciones autonómicas. En primer lugar, prescinde de la diferenciación entre viviendas unifamiliares -aisladas, pareadas o entre medianeras-y apartamentos sitos en inmuebles sometidos al régimen de la propiedad horizontal ${ }^{34}$, permitiendo que las viviendas particulares de uso turístico puedan pertenecer a ambas categorías. Y, en segundo lugar, no establece límites temporales mínimos a la estancia de los usuarios en las viviendas particulares, como hacía el Decreto 79/2014, de 10 de julio, que regula los apartamentos turísticos y las viviendas de uso turístico de la Comunidad de Madrid. Esta Comunidad Autónoma prohibía la contratación de estancias inferiores a cinco días (art. 17.3) hasta la reciente anulación de este precepto por parte del Tribunal Superior de Justicia de Madrid (sentencias no 291/2016 y 292/2016, ambas de 31 de mayo ${ }^{35}$ ), el cual considera que tal "[...] limitación temporal resulta contrari[a] a la normativa comunitaria y estatal señalada y constituye una restricción injustificada y un obstáculo al mantenimiento de la competencia efectiva en el mercado entre los operadores turísticos en materia de alojamiento" (Fundamento de Derecho séptimo de ambas sentencias).

\section{REQUISITOS DE ACCESO AL MERCADO PARA LAS VIVIENDAS PARTI- CULARES DEDICADAS AL USO TURÍSTICO EN ANDALUCÍA}

Para iniciar legalmente su actividad, las viviendas turísticas deben someterse a la potestad de policía de las Administraciones públicas, materializada en este caso en un instrumento de control de la actividad a posteriori (art. 9). El Decreto andaluz considera suficiente que su titular o explotador formalice ante el Órgano competente en materia de turismo la correspondiente declaración responsable ${ }^{36}$, en la que deberá manifestar

34 Tal y como hace el Decreto 20/2015, de 17 de abril, de principios generales y directrices de coordinación en materia turística; de regulación de órganos asesores, de coordinación y de cooperación del Gobierno de las Illes Balears, y de regulación y clasificación de las empresas y de los establecimientos turísticos, dictado en desarrollo de la Ley 8/2012, de 19 de julio, de Turismo de las Illes Balears (art. 106.1). En esta Comunidad Autónoma la cesión turística de apartamentos particulares seguirá rigiéndose por la LAU.

35 El recurso que da lugar al primero de los pronunciamientos fue interpuesto por la Comisión Nacional del Mercado y de las Comunicaciones (CNMC), y el segundo por la asociación de propietarios de viviendas particulares de uso turístico Madrid Aloja.

36 Cuyo concepto genérico en relación al procedimiento administrativo común se encuentra recogido en el artículo 69 de la nueva Ley 39/2015, de 1 de octubre, del Procedimiento Administrativo Común de las Administraciones Públicas. 
-bajo su responsabilidad- el cumplimiento de los requisitos establecidos en el Decreto 28/2016. El contenido mínimo de este documento estará conformado por los datos identificativos de la vivienda (incluida la referencia catastral y su capacidad en función de la licencia de ocupación o instrumento equivalente), de la persona propietaria y de su domicilio a efectos de notificaciones, y de la persona o entidad explotadora (en caso de no coincidir con la anterior) y título que la habilite. Al tratarse de un instrumento de control a posteriori, el interesado cumple el requisito de acceso a la actividad con la entrega de su declaración responsable en el registro administrativo, por lo que su actividad se considera ajustada a Derecho desde ese mismo instante, con independencia de que, en un momento posterior, la Administración pública proceda a contrastar con la realidad la veracidad de lo manifestado por aquél. Así lo reconoce implícitamente el Decreto andaluz al señalar que desde la formalización de la declaración responsable, el alojamiento puede "[...] publicitarse a partir de ese momento como vivienda con fines turísticos".

El ejecutivo andaluz prescinde -como ya lo hizo en su momento el propio Real Decreto 2877/1982, de 15 de octubre, de ordenación de apartamentos turísticos y de viviendas turísticas vacacionales (art. 18)- de los instrumentos de intervención a priori, que requieren la previa comprobación, por parte de la Administración, de la adecuación de la actividad al Ordenamiento jurídico como requisito ineludible para el inicio de la actividad, ejemplo de los cuáles son las tradicionales autorizaciones o licencias. Se ajusta así a lo exigido por la citada Directiva europea de servicios -2006/123/CE, de 12 de diciembre, o Directiva Bolkestein-, que establece la primacía de los instrumentos de control a posteriori, admitiendo las autorizaciones y licencias solamente de forma excepcional, a modo de último recurso ${ }^{37}$, cuando se cumplan una serie de condiciones taxativamente fijadas por la propia Directiva ${ }^{38}$. Como se ha apuntado supra, la Comisión Europea aplica esta filosofía al ámbito turístico, señalando en su Agenda europea para la economía colaborativa que los Estados miembros pueden someter, tanto a los proveedores de servicios - propietarios de las viviendas- como a las falsas plataformas colaborativas -intermediarios que ejercen un control significativo sobre los primeros-, a requisitos de acceso al mercado - market access requirements-, y que éstos pueden ser tanto a priori como a posteriori, siempre que, en el primer caso, se apliquen de forma restrictiva y excepcional, siendo necesaria su justificación y proporcionalidad, en la línea marcada por la Directiva de servicios, de modo que se tome en consideración las

37 Esta filosofía es recogida igualmente por la LTA, la cual dispone en relación a los servicios turísticos que "[c]on carácter general, la presentación de una declaración responsable [...], o la comunicación o el otorgamiento de una habilitación [...], permitirán acceder al ejercicio de la actividad” (art. 30.2).

38 Previstas en su artículo 10: solamente resultará admisible la exigencia de autorización en supuestos justificados por una razón imperiosa de interés general -entre las que cita expresamente el orden público, la seguridad pública, la protección civil, la salud pública, la preservación del equilibrio financiero del régimen de seguridad social, la protección de los consumidores, de los destinatarios de servicios y de los trabajadores, las exigencias de la buena fe en las transacciones comerciales, la lucha contra el fraude, la protección del medio ambiente y del entorno urbano, la sanidad animal, la propiedad intelectual e industrial, la conservación del patrimonio histórico y artístico nacional y los objetivos de la política social y cultural; art. 4.8- y siempre que no se trate de una medida de carácter discriminatorio y sus criterios resulten proporcionados, claros e inequívocos, objetivos, transparentes y accesibles, y conocidos con antelación. 
particularidades del modelo de negocio del servicio en cuestión, sin favorecer ningún concreto modelo sobre los demás (Comisión Europea: 2016, 3-4) ${ }^{39}$.

El Decreto andaluz solamente se ocupa de los proveedores de servicios, sin regular el acceso al mercado de los intermediarios turísticos (ya se traten de verdaderas o falsas plataformas colaborativas). En consideración a aquéllos, no considera justificable la exigencia de autorización previa, razonando los requisitos requeridos para la comercialización turística de las viviendas particulares en que éstos son proporcionados a la naturaleza de la actividad y "[...] son más reducidos que los que se imponen a otros alojamientos turísticos [...]", al tratarse de requisitos "[...] relacionados más directamente con la prestación del servicio, la dotación de una calidad básica de la oferta [...] [y] la atención y el derecho de información de las personas usuarias" (Exposición de motivos, párrafo décimo). De esta forma, la norma andaluza se ajusta al principio de intervención mínima propugnado por el Derecho de la Unión Europea, primando la declaración responsable sobre otros medios de control de las actividades privadas más restrictivos y fijando unos requisitos de funcionamiento reducidos al mínimo necesario para garantizar un nivel aceptable de comodidad, seguridad y salubridad del alojamiento.

Una vez declarada la dedicación turística de la vivienda privada ante la Administración competente, se procederá de oficio a su inscripción en el Registro de Turismo de Andalucía, debiendo comunicarse las altas y bajas a las corporaciones municipales donde éstas se ubiquen así como a la Consejería competente en materia de vivienda. Además, el código de inscripción del citado registro deberá indicarse en toda promoción o publicidad de la vivienda realizada por cualquier medio (arts. 3.3 y 3.4).

\section{REQUISITOS PARA LA COMERCIALIZACIÓN DE LAS VIVIENDAS PAR- TICULARES DE USO TURÍSTICO EN ANDALUCÍA}

Como se ha adelantado en el epígrafe anterior, el Decreto andaluz justifica la elección de los requisitos de funcionamiento de las viviendas particulares dedicadas al uso turístico (art. 6) en su carácter proporcional a la naturaleza de la actividad que en ellos se realiza, siendo menos exigentes que los requeridos a otros establecimientos de alojamiento turísticos de naturaleza similar, esto es, los apartamentos turísticos. En primer lugar, las viviendas particulares que pretendan dedicarse al uso turístico deberán contar con licencia de ocupación (lo que está generando ya algunos problemas prácticos derivados de la carencia de este documento en relación a viviendas antiguas o ubicadas en inmuebles sometidos al régimen de propiedad horizonal) y cumplir en todo momento con las condiciones técnicas y de calidad exigible a cualquier vivienda ("cláusula de progreso"). No debe olvidarse que el Decreto andaluz recuerda en su artículo 2.2 que estas viviendas "[...] se someterán igualmente a la normativa sectorial que, en su caso le sea de aplicación". Deberán, además, encontrarse suficientemente amuebladas y dotados de los aparatos y enseres necesarios para su uso inmediato y acorde al número de plazas de que dispon-

39 Además, en relación a los proveedores de servicios profesionales, la Comisión admite las prohibiciones absolutas y los restricciones cuantitativas únicamente como una medida de último recurso, cuando otras medidas menos restrictivas no resulten suficientes. 
gan, en consonancia de la exigencia contenida por la propia LAU ${ }^{40}$. Las habitaciones deberán contar con ventilación directa al exterior o a patios, así como con sistemas de oscurecimiento de las ventanas (salvo que se trate de bienes protegidos por la legislación de patrimonio histórico y cultural). Si las viviendas son arrendadas durante los meses de mayo a septiembre tendrán que contar con sistemas de refrigeración por elementos fijos, y si lo hacen durante los meses de octubre a abril, de calefacción (requisitos de los que se puede prescindir en el mismo caso que el supuesto anterior). Finalmente, las viviendas deberán disponer de botiquín de primeros auxilios, Hojas de Quejas y Reclamaciones (con su correspondiente cartel anunciador en lugar visible) y un servicio de limpieza de la vivienda a la entrada y salida de nuevos clientes. Este servicio de limpieza en ningún caso puede asimilarse a los servicios complementarios al alojamiento que caracterizan a los apartamentos turísticos, pues no se prestan directamente a sus usuarios durante su estancia, sino a su propietario, con el objetivo de que la vivienda esté en perfectas condiciones de disfrute para los siguientes usuarios.

El resto de requisitos pertenecen a la categoría de las obligaciones de información: la vivienda debe disponer de información turística en soporte físico o electrónico de las zonas de ocio, restaurantes y cafeterías, comercios y tiendas de alimentación, aparcamientos más próximos, servicios médicos, medios de transporte urbano, plano de la localidad y guía de espectáculos. También debe facilitarse a los usuarios un número de teléfono en el que puedan ser atendidas y resueltas de forma inmediata cualquier consulta o incidencia relativa a la vivienda, así como información e instrucciones relativas al funcionamiento de electrodomésticos u otros dispositivos que lo requieran para su correcta utilización. Finalmente, debe informarse a los usuarios de las normas internas relativas al uso de las habitaciones, dependencias y equipos de la vivienda, así como la admisión de mascotas, restricciones para fumadores y zonas de uso restringido.

Todos los requisitos referidos deberán ser cumplidos sin excepción por todas las viviendas, sin que sea posible, por tanto, su dispensa o compensación con otros requisitos. Sin embargo, el Decreto andaluz prescinde de algunos requisitos previstos en otras regulaciones autonómicas, como placas identificativas en el exterior de la vivienda y póliza de seguro frente a daños corporales o materiales que puedan sufrir los usuarios durante su estancia ${ }^{41}$, cierre interior de seguridad en las puertas de acceso e iluminación para la lectura junto a cada cama ${ }^{42}$, extintores, servicio público o privado de recogida de basuras, y acceso señalizado y practicable para vehículos tipo turismo ${ }^{43}$, medidas de prevención y protección contra incendios ${ }^{44}$, acceso wifi a Internet ${ }^{45}$, armario ropero, perchas y altura mínima de las estancias ${ }^{46}$, entre otras.

40 El Decreto redunda en esta exigencia al disponer que las viviendas deberán contar ropa de cama, lencería y menaje de casa en general en función de la ocupación de la vivienda, además de un juego de reposición (art. $6 i$ ).

\footnotetext{
41 Decreto balear 20/2015, de 17 de abril (arts. 107 y 108).

42 Decreto canario 113/2015, de 22 de mayo (art. 10).

43 Decreto asturiano 48/2016, de 10 de agosto (art. 5).

44 Decreto cántabro 19/2014, de 13 de marzo (art. 9).

45 Decreto madrileño 79/2014, de 10 de julio (art. 18.3).

46 Decreto gallego 52/2011, de 24 de marzo (art. 7).
} 


\section{EL CONTRATO DE CESIÓN DE VIVIENDAS PARTICULARES DE USO TURÍSTICO EN ANDALUCÍA. DERECHOS Y OBLIGACIONES DE LAS PARTES}

Todos los usuarios de viviendas turísticas andaluzas deberán recibir, en el momento de su recepción, un documento a modo de contrato en el que consten los datos esenciales de su estancia, incluyendo el número de teléfono de contacto permanente con el responsable de la vivienda (art. 7.1) ${ }^{47}$. Como contrapartida, los usuarios deberán presentar su documento de identificación a efectos de cumplimentar un parte de entrada (art. 7.2). Con carácter general, las condiciones del contrato se regirán por lo expresamente pactado entre las partes, si bien en ausencia de pacto los responsables de la vivienda podrán exigir al usuario el pago de una reserva del precio en concepto de señal de hasta un máximo del $30 \%$ del montante total. Igualmente a falta de pacto, si el usuario cancelase la reserva, el propietario de la vivienda podrá retener hasta el 50\% de este anticipo -si la cancelación se produce antes de diez días de la fecha prevista de ocupación, si se cancela dentro de este plazo, podrá retener la totalidad del anticipo-. En correspondencia, si fuese el propietario quien cancelase la reserva, deberá devolver al usuario el anticipo recibido -y si la reserva se cancela en el citado plazo de diez días, deberá indemnizarle con el 30\% del precio de la estancia contratada- $(\text { art. 8.3 })^{48}$.

En el precio de la estancia se considera incluido el suministro de agua, energía eléctrica, calefacción, refrigeración, limpieza a la entrada de nuevos usuarios y el uso de ropa de cama y baño y de menaje (art. 8.1). Se trata de los denominados "servicios básicos", que acompañan a la cesión de la vivienda, de forma que el turista obtenga no solamente el uso pasivo del local y su mobiliario, como ocurre con el alquiler de vivienda amueblada, sino los beneficios activos y pasivos de un hogar, por lo que las prestaciones vinculadas a la cesión de la vivienda de uso turístico exceden de las propias de un arrendamiento ordinario, siendo, por el contrario, propias de la hostelería (Franch Fluxá y Ribas Conrado, 2013: 42-43) $)^{49}$. Tales prestaciones no pueden confundirse tampoco con los servicios complementarios característicos de los apartamentos turísticos, pues éstos exceden de los habituales de un hogar, como sucede con la limpieza diaria o el servicio de recepción.

Como es habitual en las regulaciones autonómicas de este fenómeno, el Decreto andaluz no recoge un catálogo específico de derechos y obligaciones de los usuarios y explotadores de estas viviendas ${ }^{50}$, reenviando esta cuestión a la regulación general con-

47 Una copia de este documento, firmada por el usuario, deberá conservarse por el responsable de la vivienda durante un año, estando durante este tiempo a disposición de los órganos autonómicos competentes. Este documento goza de valor de prueba a efectos administrativos y la consideración de contrato (art. 7.3).

48 Salvo que, en ambos casos, la cancelación sea consecuencia de supuestos de fuerza mayor (art. 8.4).

49 Algún autor considera que la prestación de estos servicios es igualmente habitual en los arrendamientos ordinarios, por lo que niega su naturaleza turística y su capacidad para transformar el contrato de arrendamiento por temporada en un contrato de cesión de uso turístico de viviendas particulares (Martínez Cañellas, A, 2014: 169). A mi entender, se estaría equiparando erróneamente la prestación del servicio - presente en ambos supuestos- con el pago del mismo por parte del propietario de la vivienda -que solamente sucede en estos últimos, al estar incluido en el precio de la estancia-.

50 Solamente el Decreto asturiano 48/2016, de 10 de agosto, reserva uno de sus preceptos para las "obligaciones de las empresas explotadoras de las viviendas"(art. 27). 
tenida en la LTA (art. 2.4). Los usuarios de tales viviendas se convierten así en usuarios privilegiados, pues dejan de estar sometidos de forma genérica a la normativa sobre protección de consumidores y usuarios, contando a partir de ahora con un estatuto exclusivo y reforzado, tal y como sucede con el resto de usuarios de servicios turísticos. El Decreto andaluz se limita a prever las consecuencias del incumplimiento de las reglas de convivencia (art. 2.5): el responsable de la vivienda podrá denegar la permanencia en la misma de los usuarios y requerir su abandono en un plazo de veinticuatro horas. También se prohíbe la discriminación de cualquier naturaleza en el acceso a las viviendas (art. 2.3) y la sobrecontratación (art. 2.6).

\section{INSPECCIÓN Y RÉGIMEN SANCIONADOR}

El Decreto andaluz estableció una vacatio legis de tres meses desde su publicación (Disposición final cuarta). Una vez pasado este plazo, la prestación del servicio de alojamiento en viviendas particulares sin haber realizado la pertinente declaración responsable se considera actividad clandestina (art. 11) ${ }^{51}$, tipificándose como infracción grave conforme al artículo 71.1 LTA. Esta categoría de infracciones están sancionadas con pena de multa de 2.001 a $18.000 €$ y suspensión temporal del ejercicio de servicios turísticos (o clausura temporal del establecimiento o de la unidad alojativa) por un periodo comprendido entre seis meses y tres años (art. 78.3 LTA $)^{52}$. El Decreto andaluz se remite en bloque a la LTA en relación al régimen sancionador (art. 10.2), fijando como responsables de las infracciones cometidas en este ámbito a los titulares de las viviendas clandestinas (art. 73 LTA), pero sin extender tal responsabilidad de forma expresa a los facilitadores de su comercialización, esto es, a las empresas mediadoras entre los propietarios de las viviendas y sus usuarios, como se ha venido reclamando desde diferentes ámbitos (Cehat, 2013: 9; Franch Fluxá y Ribas Conrado, 2013: 50).

Por último, las labores de inspección de estos establecimientos son encomendadas de forma genérica a la Consejería competente en materia de turismo, que "[...] ejercerá [...] las funciones de comprobación y control del cumplimiento de los establecidos en la presente norma" de acuerdo con la LTA y el Decreto 144/200, de 3 de junio, de Inspección de Turismo, sin perjuicio de las competencias de control e inspección que tengan atribuidas otras Consejerías o Administraciones públicas (art. 10.1). La persona que explote la vivienda deberá facilitar a los servicios de inspección el ejercicio de sus funciones (art. 10.3).

51 Si bien los propietarios disponen de un plazo de un año desde la entrada en vigor del Decreto 28/2016 (hasta el 11 de mayo de 2017) para adaptar sus viviendas al apartado $d$ del artículo 6, esto es, contar con los sistemas de refrigeración por elementos fijos y calefacción (Disposición transitoria única, número 2).

52 Incluso, podrá llegarse a la clausura definitiva del establecimiento y, en su caso, a la cancelación de la inscripción en el Registro de Turismo de Andalucía, cuando el responsable haya sido sancionado dos o más veces en el transcurso de tres años consecutivos por la comisión de infracciones muy graves, mediante resolución firme en vía administrativa, y se produzcan perjuicios graves para los intereses turísticos de Andalucía (art. 78.3 LTA in fine). 


\section{REFLEXIÓN FINAL}

El reglamento andaluz sobre viviendas particulares de uso turístico se mantiene dentro de los cauces marcados por sus antecesores en otras Comunidades Autónomas, tanto en lo que se refiere a los requisitos de acceso al mercado -declaraciones responsables- como a los referidos a su comercialización. Con respecto a estos últimos el ejecutivo andaluz prescinde de listados pormenorizados y exhaustivos sobre exigencias estructurales de la vivienda y equipamiento, optando por conceptos jurídicos indeterminados como "suficientemente amueblada" o "ropa de cama, lencería y menaje de casa en general", lo cual otorga una gran libertad a los propietarios a la hora de acondicionar la vivienda para su explotación turística. Entre las novedades más importantes de la norma andaluza, que se han ido señalando a lo largo de este trabajo, estarían la posibilidad de ceder la vivienda por habitaciones, en contra del criterio de la LAU; o la consideración expresa del alquiler de viviendas turísticas como un servicio turístico al mismo nivel que los recogidos en la Ley del Turismo de Andalucía. Entre las ausencias más destacadas, algunos requisitos para la comercialización de la vivienda, como la póliza de seguro frente a daños corporales o materiales que puedan sufrir los usuarios durante su estancia, algunos elementos de protección frente a incendios -extintores o mantas ignífugas- o el acceso wifi a Internet. También se echa en falta, como ocurre en resto de Comunidades Autónomas, la existencia de un mecanismo jurídico que concilie definitivamente las exigencias del planeamiento urbanístico con la naturaleza turística de estas viviendas. Finalmente, la doctrina ha puesto de manifiesto la conveniencia de extender la responsabilidad por la comercialización de viviendas clandestinas a los canales de intermediación turística, de forma que los sujetos susceptibles de ser sancionados por esta conducta no sean únicamente sus propietarios, sino también los canales que comercialicen viviendas no adaptadas a las exigencias del Decreto 28/2016. Sin embargo, tal ausencia estaría justificada por la propia configuración del Decreto andaluz, cuyo ámbito objetivo se limita al servicio turístico -la cesión de la vivienda particular- y a la identificación genérica de sus cauces de comercialización, pero sin contener una regulación pormenorizada de estos últimos. En relación a esta cuestión, la Agenda europea para la economía colaborativa constituye una magnífica orientación para los decisores públicos que se decidan a reglamentar los canales de comercialización turística, tanto de forma genérica para el conjunto de servicios turísticos, como específicamente para las viviendas particulares de uso turístico.

\section{BIBLIOGRAFÍA}

BLANCO CARRASCO, M. (2014): La reforma de arrendamientos urbanos efectuada por la Ley 4/2013, Reus.

BOSTMAN, R. (2013): «The shared economy lacks a shared definition», publicación online, fastcoexist.com, 21 de noviembre.

CALDERÓN MONGE, M.E., IZQUIERDO YUSTAQ, A. y RUIZ VEGA, A.V. (2007): «La reserva de alojamientos a través de Internet: una aplicación al turismo urbano y al turismo rural», en El comportamiento de la empresa ante entornos dinámicos: XIX Congreso anual y XV Congreso Hispano Francés de AEDEM, Vol. 2 (Comunicaciones), 25 pp. 
CAMPUZANO TOMÉ, H. (2015): «El alquiler de viviendas de uso turístico a partir de la Ley 4/2013: la necesaria interpretación conjunta de la LAU y de la legislación turística autonómica», Revista Crítica de Derecho Inmobiliario, no 749, pp. 1199-1246.

CEHAT (2013): Identificación de las mejores prácticas internacionales en la regulación de la oferta de vivienda particular para uso turístico.

COMISIÓN EUROPEA (2016): Comunicación de 2 de junio de 2016 al Parlamento Europeo, Consejo, Comité Económico y Social, y Comité de las Regiones "Una agenda europea para la economía colaborativa".

DOMÉNECH PASCUAL, G. (2015): «La regulación de la economía colaborativa (el caso «Uber contra el taxi»)», la Revista CEFLegal, n 175-176, pp. 61-104.

ESADE (2015): Impacto social y económico de las viviendas de uso turístico en España. Disponible en http://es.slideshare.net/ESADE/estudio-impacto-viviendasturisticasespana/1.

EXCELTUR (2015): Impactos sociales y económicos sobre los destinos españoles derivados del exponencial aumento del alquiler de viviendas turísticas de corta duración, impulsado por los nuevos modelos y canales de comercialización P2P.

FRANCH FLUXÁ, J. y RIBAS CONRADO, J. F. (2013): «El alquiler de viviendas para uso vacacional. Perspectiva actual, problemas y propuestas legales», Estudios Turísticos, $\mathrm{n}^{\circ} 195$, pp. 33-57.

FUENTES-LOJO RIUS, A. (2016): «Prohibición de explotación turística de la vivienda por ser contraria a la convivencia normal de la comunidad de propietarios», Diario La Ley, $\mathrm{n}^{\circ}$ 8709, Sección Tribuna, 24 de febrero (Ref. D-83).

GILI I FERNÁNDEZ, M. (2003): «Las viviendas de segunda residencia ¿Ocio o negocio?», Scripta Nova. Revista Electrónica de Geografía y Ciencias Sociales, Vol. VII, $\mathrm{n}^{\mathrm{o}} 146$ (052), pp. 1-8.

GISMONDI, R. y MIRTO, A. P. (2002): «El turismo en los alojamientos colectivos y privados en Italia: definiciones, clasificaciones y técnicas de estimación», Estudios Turísticos, $\mathrm{n}^{\mathrm{o}}$ 151, pp. 51-85.

GOUDIN, P. et al (2016): The cost of non-Europe in the Sharing Economy. Economic, social and legal challenges and opportunities, European Parliamentary Research Service (EPRS), enero.

GUEVARA PLAZA, A. J. y CEREZO MEDINA, A. (2015): «El papel estratégico de las tecnologías de la información y las comunicaciones en el turismo», International Journal of Information Systems and Software Engineering for Big Companies, vol. 2, $\mathrm{n}^{\mathrm{o}} 2$, pp. 52-69.

GUILLÉN NAVARRO, N.A. (2015): «La vivienda de uso turístico y su incidencia en el panorama normativo español», Revista Aragonesa de Administración Pública, $\mathrm{n}^{\circ}$ 45-46, pp. 101-144.

GUILLÉN NAVARRO, N.A. e ÍNIIGUEZ BERROZPE, T. (2015): «Viviendas de uso turístico en el nuevo entorno P2P. Retos sociojurídicos para el consumo colaborativo en el alojamiento turístico», Estudios Turísticos, n 205 , pp. 9-34.

MARTÍNEZ CAÑELLAS, A. (2014): «La cesión del uso de la vivienda a no residentes: contrato de alojamiento (de estancias turísticas) en viviendas y el contrato de arrendamiento de temporada, conforme a la Ley de Turismo de las Islas Baleares tras la 
reforma de la Ley de Arrendamientos Urbanos», Boletín de la Academia de jurisprudencia y legislación de las Illes Balears, XV, Mesa redonda sobre arrendamientos turísticos, pp. 151-176.

MINISTERIO DE INDUSTRIA, ENERGÍA Y TURISMO (2012): Plan Nacional e Integral de Turismo (PNIT) 2012-2015.

ROMÁN MÁRQUEZ, A. (2014): «Las viviendas particulares dedicadas a la actividad de alojamiento turístico. Su exclusión de la Ley de Arrendamientos Urbanos», Revista Internacional de Doctrina y Jurisprudencia, vol. $6, \mathrm{n}^{\circ}$ 1, Universidad de Almería, 2014, pp. 1-24.

ROMÁN MÁRQUEZ, A. (2017): «Los Poderes Públicos ante el fenómeno de las viviendas particulares dedicadas al uso turístico y la irrupción de la denominada "economía colaborativa" en este sector. Una aproximación a la posición de la Unión Europea, el legislador español y los ejecutivos autonómicos», en VVAA, Los retos actuales del Derecho Administrativo. Estudios en homenaje al Profesor José Luís Carro Fernández-Valmayor, (en prensa).

SERRANO MARTÍNEZ, J.M. (2011): «La vivienda en España dentro del nuevo modelo económico. El papel y los límites del sector turístico ¿Hacia el declinar de un ciclo?», Cuadernos de Turismo, $\mathrm{n}^{\circ}$ 27, pp. 855-874.

VERDERA IZQUIERDO, B. (2009): «El arrendamiento de temporada frente a las estancias turísticas en viviendas», El consultor inmobiliario, $\mathrm{n}^{\circ} 107$, pp. 3-19.

VVAA (2013): «Modificaciones y novedades de la Ley 4/2013 en Arrendamientos Urbanos», en Cuaderno de arrendamientos urbanos, $\mathrm{n}^{\circ} 318$, pp. 12-14. 
